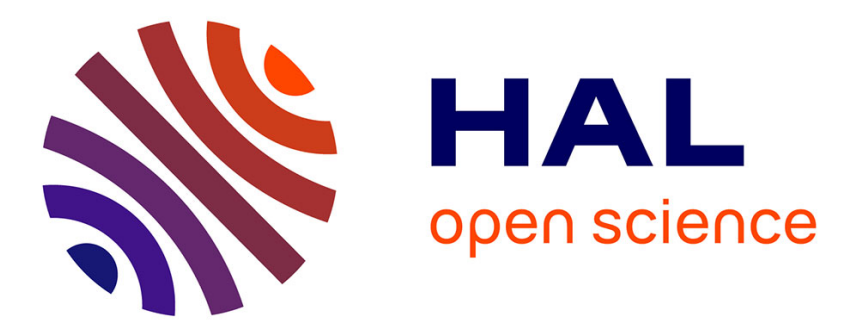

\title{
Plastic shearing at high and very high strain rates
}

J. Klepaczko

\section{To cite this version:}

J. Klepaczko. Plastic shearing at high and very high strain rates. Journal de Physique IV Proceedings, 1994, 04 (C8), pp.C8-35-C8-40. 10.1051/jp4:1994804 . jpa-00253334

\section{HAL Id: jpa-00253334 https://hal.science/jpa-00253334}

Submitted on 1 Jan 1994

HAL is a multi-disciplinary open access archive for the deposit and dissemination of scientific research documents, whether they are published or not. The documents may come from teaching and research institutions in France or abroad, or from public or private research centers.
L'archive ouverte pluridisciplinaire HAL, est destinée au dépôt et à la diffusion de documents scientifiques de niveau recherche, publiés ou non, émanant des établissements d'enseignement et de recherche français ou étrangers, des laboratoires publics ou privés. 


\title{
Plastic shearing at high and very high strain rates
}

\author{
J.R. Klepaczko
}

Laboratoire de Physique et Mécanique des Matériaux, UA 1215 du CNRS, Institut Supérieur de Génie Mécanique et Productique, Faculté des Sciences, Université de Metz, Ile du Saulcy, 57045 Metz cedex I, France

\begin{abstract}
Résumé : Nous analysons la déformation de cisaillement pour différentes vitesses de chargement dans le domaine des grandes et très grandes vitesses de déformation. Ainsi, nous présentons brièvement les différentes techniques expérimentales utilisées dans ce domaine. Une nouvelle technique expérimentale basée sur l'impact direct utilisée en double cisaillement ainsi que la géométrie modifiée de l'éprouvette sont discutées. Pour étudier le cisaillement simple, nous avons développé un modèle unidimensionnel où la loi de comportement tient compte de la sensibilité à la vitesse de déformation et à la température. Pour différentes vitesses de déformation, nous avons discuté et déterminer les conditions d'instabilités dans le cas du cisaillement adiabatique. Finalement dans le cas de la propagation unidimensionnelle des ondes plastiques, nous avons analysé la déformation engendrée par les instabilités thermoplastiques. Nous présentons une analyse précise sur la vitesse critique d'impact dans le cas du cisaillement. ainsi, nous avons effectué une comparaison entre les résultats théoriques et expérimentaux.
\end{abstract}

\begin{abstract}
Shear straining at different velocities, including high and very high strain rates, is discussed. Some experimental techniques which allows for experiments at high and very high strain rates are briefly reviewed. A new experimental technique based on direct impact on Modified Double Shear a specimen (MDS) is also reviewed. A one-dimensional model for simple shear is applied together with a constitutive relation which takes into account rate and temperature sensitivity a generalised condition for instability of adiabatic shearing at different rates has been derived and discussed. Finally, an analysis of deformation trapping in shear due to thermoplastic instability in one-dimensional plastic wave propagation is analysed. The critical impact velocity in shear is analysed in detail and values are compared with preliminary experiments.
\end{abstract}

\section{INTRODUCTION.}

Materials testing in shear at different strain rates and temperatures can provide fundamental information needed to develop constitutive relations. However, when the nominal strain rate is high enough, adiabatic instability and strain localization can occur. Still at higher strain rates in shear, for example $10^{4} \mathrm{~s}^{-1} \leq \dot{\Gamma} \leq 10^{6} \mathrm{~s}^{-1}$, plastic waves in a deformed material can completely change the mechanics of deformation. It is well know that experiments at high strain rates, $10^{3} \mathrm{~s}^{-1} \leq \dot{\Gamma} \leq 10^{6} \mathrm{~s}^{-1}$, constitute a formidable task concerning their technical difficulties, and only few reliable configurations are available. Most experimental studies of both constitutive modeling and adiabatic instabilities make use of the Split Hopkinson Torsion Bar (torsional Kolsky apparatus), for example [1-6]. This experimental technique uses a thin tubular specimen of short length. Such a test with SHTB has a very limited range (in the logarithmic scale of the nominal strain rates), usually around $10^{3} \mathrm{~s}^{-1}$. Another experimental technique is the pressureshear impact configuration, which permits conducting constant strain rate tests and strain rate change tests at shear rates up to $10^{6} \mathrm{~s}^{-1}$, [7]. The specimen of very small thickness is sandwiched between two hard elastic plates to impose conditions of simple shear at very high strain rates by an oblique impact. Although the pressure-shear impact technique assures very high shearing rates, maximum strains are limited to the order of a few percent.

One of the most promising specimen configurations which can be applied at low, medium and high strain rates in shear is the Double-notch Shear specimen. Such a specimen was first introduced in [8] to study dynamic plasticity of single crystals. Later the DS specimen was applied with the loading scheme in compression consisting of the incident Hopkinson bar and transmitter Hopkinson tube, [9]. Due to the small gauge length $(-0.84 \mathrm{~mm})$ and application of a drop-weight tester with the initial mass velocities of the incident bar from -1.2 to $-11.0 \mathrm{~m} \mathrm{~s}^{-1}$, the nominal shear strain rates achieved were in excess of $10^{4} \mathrm{~s}^{-1}$. Determination of higher strains in shear than a few percent from DS specimen used in [9] leads to large 
errors due to non-uniform shear and severe plastic deformation in the specimen supports. More advanced plastic strains in the DS specimen were analysed in [10] using an FE method. It was found that the calibration factors for stress and strain at larger strains are not constant, and there is no simple relation between external conditions of loading and stress-strain characteristics.

\section{NEW CONFIGURATION IN IMPACT SHEARING}

Since there is great interest in the study of dynamic plasticity at high strain rates and at large strains from one side and adiabatic instabilities from the other, a new configuration for a direct impact on a Modified Double Shear specimen has recently been developed, $[10,11]$.

Because description of the experimental setup and the test theory have been published elsewhere, only a brief summary of this new experimental technique will be given here. The MDS specimen is loaded by the direct impact, as is shown in Fig.1. The direct impact of a flat-ended bar on the MDS specimen gives more flexibility in programming of the nominal strain rate in shearing, by simply changing the impact velocity. Also the risetime of the incident wave which is inevitably present in the case of the bar-tube configuration is practically eliminated in the direct impact setup. The flat-ended projectiles of different length and diameter $d_{p}=10 \mathrm{~mm}$ are launched from an air gun with desired velocity $V_{0} ; 1 \mathrm{~m} / \mathrm{s} \leq \mathrm{V}_{0} \leq 200$ $\mathrm{m} / \mathrm{s}$. The impact velocity $V_{0}$ is measured by the setup consisting of three sources of light $L$ fiber optic leads $1,2,3$, three independent photodiodes $\mathrm{F}$ and two time counters $\mathrm{TC}_{1}$ and $\mathrm{TC}_{2}$.

\section{Fig.1}

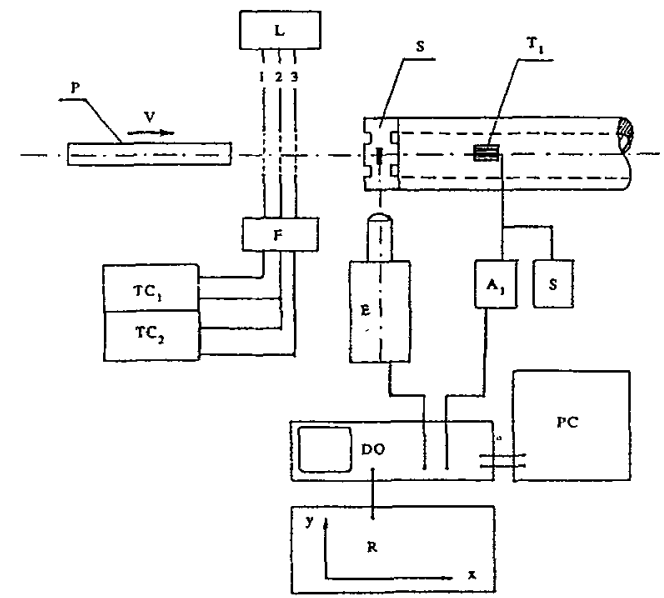

Axial displacement $U_{x}(t)$ of the central part of the MDS specimen is measured as a function of time by an optical displacement transducer $\mathrm{E}$, acting as a non-contact displacement gage. The optical transducer reacts to the axial movements of a small black and white target cemented to the central part of the MDS specimen.

Axial force transmitted by the specimen symmetric supports can be determined as a function of time from the transmitted longitudinal elastic wave $\varepsilon_{T}(t)$ measured by strain gages $T 1, D C$ supply unit $S$ and amplifier A1. All electric signals, that is voltages of displacement and transmitted wave, are recorded by digital oscilloscope DO and stored in the computer hard disk PC for further analyses. After signal calibrations and elimination of time, a force-displacement curve can be constructed for the MDS specimen and $\tau(\Gamma)$ or $\dot{\Gamma}(\Gamma)$ characteristics can be determined, where $\tau$ is the shear stress and $\Gamma$ is the shear strain, $\dot{\Gamma}$ $=\mathrm{d} \Gamma / \mathrm{dt}$. The exact theory of this test is given elsewhere, [11].

Due to modification of the geometry of the double shear specimen, that is, increase of the deforming part to $2.0 \mathrm{~mm}$ (gage length), stress concentrations in the notch have been relieved and a more uniform strain field achieved. In addition, the external parts of the MDS specimen have been extended and they are rigidly clamped before each test to the Hopkinson tube. Such a procedure substantially reduces rotations of the external parts of the MDS specimen during plastic deformation, and equalizes the plastic field over the gage length. The technique has already shown its usefulness in testing of materials at high strain rates in shearing, up to $-10^{5} \mathrm{~s}^{-1}$.

\section{SOME EXPERIMENTAL RESULTS}

A series of experiments with different impact velocities, up to $100 \mathrm{~m} / \mathrm{s}$, were performed on low- 
alloy steel XC 18 (French standards) of the following composition in percent : C $0.17 ; \mathrm{Mn} 0.58 ; \mathrm{Si} 0.21$; $\mathrm{S} 0.032$; P 0.024 . After machining all specimens were vacuum annealed at $-1000 \mathrm{~K}$ for $11 / 2 \mathrm{~h}$ and

furnace cooled. The rate sensitivity of this steel was within the range of strain rates $10^{2} \mathrm{~s}^{-1} \leq \dot{\Gamma} \leq 10^{5} \mathrm{~s}^{-1}$ as reported in [11]. Those experiments have revealed a high strain rate sensitivity at strain rates above

- $10^{3} s^{1}$. For example, the coefficient of pseudo-viscosity $\zeta$ in the relation

$$
\tau_{\mathrm{y}}=\hat{\tau}_{\mathrm{y}}+\zeta_{\mathrm{y}} \dot{\Gamma}
$$

is $14.3 \mathrm{kPa}$.s for the upper yield point and $4.0 \mathrm{kPa} . \mathrm{s}$ for the lower yield stress, [11].

Another series of experiments was carried out on VAR 4340 steel, heat treated up to $\sim 52 \mathrm{HRC}$. It was found that the coefficient of pseudo-viscosity $\zeta$ for this steel (at the point of fracture with very limited plastic deformation) was $\zeta_{F} \approx 6.45 \mathrm{kPa} . \mathrm{s}$.

The test performed on both steels at very high nominal strain rates have revealed a critical impact velocity in shear. The critical impact velocity in shear is the result of the deformation trapping due to adiabatic instability and strain localization superimposed on plastic wave propagation in shear. For the steels tested the critical impact velocities could be estimated as $\vartheta_{\mathrm{cr}} \approx 90 \mathrm{~m} / \mathrm{s}$ for XC18 and $\vartheta_{\mathrm{cr}} \approx 140 \mathrm{~m} / \mathrm{s}$ for VAR $4340(-52 \mathrm{HRC})$. Those values of $\vartheta_{\mathrm{c}}$ give respectively the following values of the nominal strain rates $: \dot{\Gamma}_{\mathrm{c}} \approx 4.5 \times 10^{4} \mathrm{~s}^{-1}$ and $\dot{\Gamma}_{\mathrm{c}} \approx 8 \times 10^{4} \mathrm{~s}^{-1}$ for 4340 steel. Experimental evidence for the critical impact velocity in shear is shown in Fig. 2 for XC18 steel and in Fig.3 for VAR 4340.

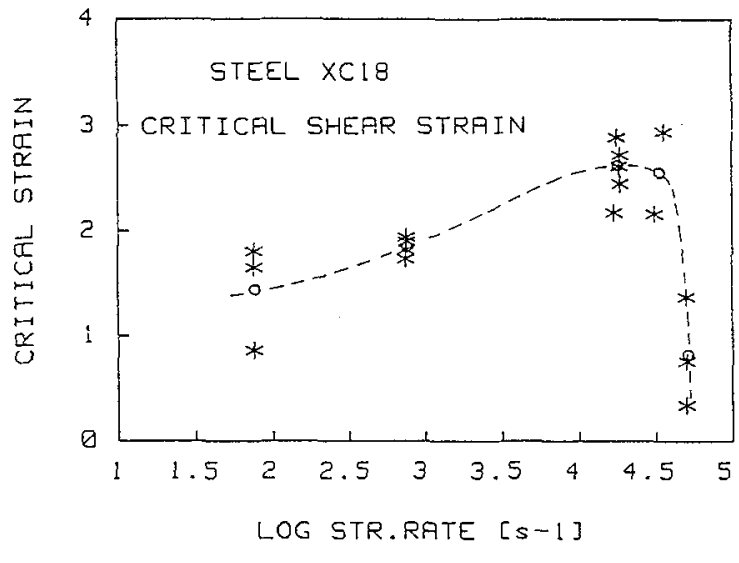

Fig.2

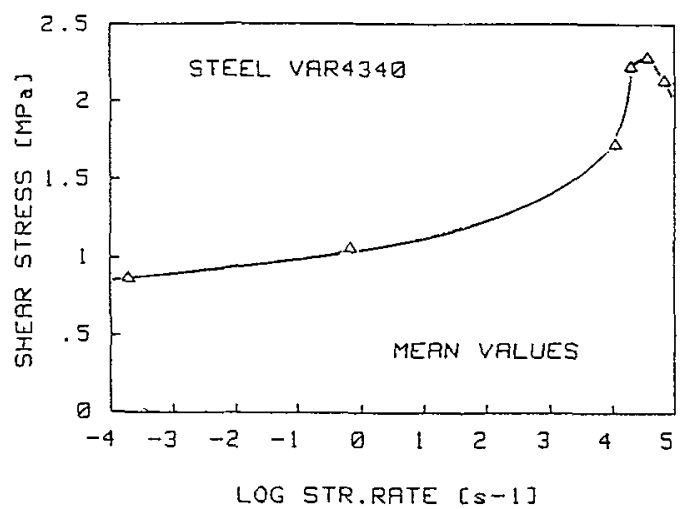

Fig. 3

Fig. 2 shows the critical strains (up to fracture) determined as a function of the nominal strain rate $\log \dot{\Gamma}$.

The mean values are indicated as circles. Indeed, at $\log \dot{\Gamma}_{c} \approx 4.65$ an abrupt decrease of the total strain (elastic plus plastic) is evident. Similarly for the VAR 4340 steel, decrease of the fracture shear stress occurs at $\log \dot{\Gamma}_{\mathrm{c}} \approx 4.8$. Because this steel was very hard an analysis of the final plastic deformation was difficult, and instead Fig. 3 was obtained. Existence of the critical impact velocity in shear is an analog to the von Kàrmàn critical impact velocity in impact tension, [12, 13].

\section{ANALYSIS OF THE CRITICAL IMPACT VELOCITY}

When the strain rate of plastic deformation is high enough a phenomenon observed is formation of the so called adiabatic shear bands. The work of plastic deformation is dissipated locally as heat, and if time of deformation is short the heating process is adiabatic. The adiabatic heating tends to reduce the flow stress which, in turn, leads to defummation instability and localization. The adiabatic shear bands form along the direction of the maximal shear stress. The condition for stability in the quasi-static conditions of deformation in shear leads to the formula.

$$
\frac{\mathrm{d} \tau}{\mathrm{d} \Gamma}=0
$$

A number of authors have used instability criterion (2), for example Recht [14] and others, in 
derivation of the critical strain $\Gamma_{c}$ at which condition (2) is satisfied. Here a more general discussion of the criterion (2) is offered. Because many authors use constitutive relations in the form of multiplication functions

$$
\tau=f_{1}(\mathrm{~T}) f_{2}(\Gamma) f_{3}(\dot{\Gamma})
$$

where $T$ is the absolute temperature, and the strain-rate and temperature history effects are neglected, the instability criterion will be derived using eqs (2) and (3). After differentiation of (3) and introduction into (2) the following relation is obtained

$$
\left(\frac{\partial \tau}{\partial \Gamma}\right) \mathrm{T}, \dot{\Gamma}+\left(\frac{\partial \tau}{\partial \mathrm{T}}\right) \Gamma, \dot{\Gamma} \frac{\mathrm{dT}}{\mathrm{d} \Gamma}+\left(\frac{\partial \tau}{\partial \dot{\Gamma}}\right) \mathrm{T}, \Gamma \frac{\mathrm{d} \dot{\Gamma}}{\mathrm{d} \Gamma}=0
$$

Condition (4) can be satisfied only in very specific processes for plastic deformation, one of them is adiabatic deformation at constant strain rate. Thus, the condition (4) reduces to

$$
\left(\frac{\partial \tau}{\partial \Gamma}\right) \Gamma, \dot{\Gamma}+\left(\frac{\partial \tau}{\partial T}\right)\left(\frac{d \tau}{d \Gamma}\right) \text { ADIABATIC } \quad=0
$$

Assuming constitutive relation (3) it follows from the principle of energy conservation

$$
\left(\frac{\mathrm{dT}}{\mathrm{d} \Gamma}\right)_{\mathrm{A}}=\frac{[1-\xi(\mathrm{T}, \Gamma)] f 1(\mathrm{~T}) f 2(\Gamma) f 3(\dot{\Gamma})}{\rho(\mathrm{T}) \mathrm{Cv}(\mathrm{T})}
$$

Where $\xi(T, \Gamma)$ is a coefficient taking into account the stored energy in the material, $\rho(T)$ is the mass density and $C_{V}(T)$ is the specific heat at constant volume. In general, both $\rho$ and $C_{V}$ are functions of the absolute temperature $T$. If the explicit forms of the partial differentials derived after (3) along with (6) are introduced into (5) the condition (5) transforms into

$$
\left(\frac{\partial f_{2}}{\partial \Gamma}\right)+\stackrel{2}{f_{2}}\left(\Gamma_{\mathrm{c}}\right) f_{3} \dot{\Gamma}\left(\frac{\partial f_{1}}{\partial \mathrm{T}}\right) \frac{1-\xi}{\rho \mathrm{C}_{\mathrm{v}}}=0
$$

Since only $f_{2}\left(\Gamma_{\mathrm{c}}\right)$ depends on the critical strain the explicit equation for $f_{2}\left(\Gamma_{\mathrm{c}}\right)$ is

$$
f_{2}\left(\Gamma_{\mathrm{c}}\right)=\left[-\frac{\left(\partial f_{2} / \partial \Gamma\right)}{\left(\partial f_{1} / \partial \mathrm{T}\right)} \frac{\rho \mathrm{C}_{\mathrm{v}}}{f_{3}(\dot{\Gamma})(1-\xi)}\right] 1 / 2
$$

The expression $[\cdot]^{1 / 2}$ has real and imaginary parts. Inversion of $f_{2}\left(\Gamma_{\mathrm{c}}\right)$ makes it possible to find $\Gamma_{\mathrm{c}}$,

$$
\Gamma_{c}=f_{2}^{-1}[.]^{1 / 2}
$$

Existence of the real $f_{2}\left(\Gamma_{\mathrm{c}}\right)$ is only possible if the expression [.] $]^{1 / 2}$ inside the square brackets is positive. Since $\rho, C_{v}$ and $(1-\xi)$ must be always positive and the function of strain rate sensitivity, $f_{3}(\dot{\Gamma})$, is assumed also positive, the only term which may be negative is $\left(\partial f_{2} / \partial \Gamma\right) /\left(\partial f_{1} / \partial \mathrm{T}\right)$. The most common case is the thermal softening which leads to negative value of $\left(\partial f_{1} / \partial \mathrm{T}\right)$, of course, if $\left(\partial f_{2} / \partial \Gamma\right)$ is at the same time positive. The rôle of a positive rate sensitivity is quite interesting, that is if $f_{3}(\dot{\Gamma})$ is an increasing function of strain rate $\dot{\Gamma}$. The positive rate sensitivity has a negative effect on the onset of adiabatic instability, that is, $\Gamma_{\mathrm{c}}$ is reduced when strain rate is increased.

Von Kàrmàn noted that, according to rate-independent wave theory applied to one-dimensional tension, the strain level at which the tangent modulus becomes zero propagates at zero speed. By analogy, it is possible to construct a model of the plastic wave trapping in shear, based on the criterion of adiabatic instability, eqs. (2) and (8). According to the rate-independent theory of elastic-plastic wave propagation, as applied to shear deformation, the wave equation is as follows

$$
\frac{\partial^{2}}{\partial} \frac{U}{t^{2}}=C_{2 p}(\Gamma) \frac{\partial^{2} U}{\partial y^{2}}
$$

where $U$ is displacement along $\mathrm{X}$-axis and waves propagate along $\mathrm{y}$-axis (perpendicular) ; the wave speed is defined as

$$
C_{2 p}(\Gamma)=\left(\frac{1}{\rho} \frac{d}{d} \Gamma\right)^{1 / 2}
$$


Eq. (11) reduces to $C_{2}=\sqrt{\mu / \rho}$ for the elastic case.

Along the non-linear characteristics $\mathrm{C}_{2 \mathrm{p}}= \pm(\mathrm{dy} / \mathrm{dt})$ the following relation holds

$$
d\left[\int_{0}^{\Gamma} \mathrm{C}_{2 p}(\Gamma) \mathrm{d} \Gamma \pm \vartheta\right]=0
$$

where $\vartheta$ is the mass velocity, $\vartheta=(\partial U / \partial t)$. It is clear from (2), (5) and (11) that the wave-speed is zero if condition (2) is satisfied, that is $C_{2 p}\left(\Gamma_{c}\right)=0$, and at the same time the intergral in (12) reaches the maximum value, thus

$$
\vartheta_{c}=\int_{0}^{\Gamma_{c}} C_{2 p}(\Gamma)_{\dot{\Gamma}} d \Gamma
$$

where $\Gamma_{c}$ is defined by eq (9). The wave speed in the adiabatic conditions of deformation, and $\dot{\Gamma}=$ const, can be written as

$$
C_{2 p}= \pm\left\{\frac{f_{1} f_{2} f_{3}}{\rho}\left[\frac{1}{f_{2}}\left(\frac{\partial f_{2}}{\partial \Gamma}\right)+f_{2} f_{3}\left(\frac{\partial f_{1}}{\partial T}\right) \frac{1-\xi}{\rho C_{v}}\right]\right\}^{1 / 2}
$$

Finally, the critical impact velocity in shear is given by

$$
\vartheta_{c}=\int_{0}^{\Gamma_{c}}\left\{\frac{f_{1} f_{2} f_{3}}{\rho}\left[\frac{1}{f_{2}}\left(\frac{\partial f_{2}}{\partial \Gamma}\right)+f_{2} f_{3}\left(\frac{\partial f_{1}}{\partial \mathrm{T}}\right) \frac{1-\xi}{\rho C_{\mathrm{v}}}\right]\right\}^{1 / 2} \mathrm{~d} \Gamma
$$

where the upper limit of integration is given by (9). simple.

Analytic solutions for $\Gamma_{c}, C_{2 p}(T)$ and $\vartheta_{c}$ are possible if the constitutive relation is sufficiently

For example, assuming

$$
\tau=\mathrm{BT}^{-\mathrm{v}}\left(\Gamma_{0}+\Gamma\right)^{\mathrm{n}} \dot{\Gamma}^{\mathrm{m}}
$$

explicit expressions for $\Gamma_{c}, C_{2 p}$ and $\vartheta_{c}$ are

$$
\begin{aligned}
& \Gamma c=\left[\frac{n \rho C_{v}}{(1-\xi) \dot{\Gamma}^{m} \nu \mathrm{B}}\right]^{\frac{1}{n+1}} \mathrm{~T}^{\frac{\nu+1}{n+1}} \\
& \mathrm{C}_{2 p}=\tau\left[\frac{1}{\left.\rho\left(\frac{\mathrm{n}}{\tau \Gamma}-\frac{\nu(1-\xi)}{\mathrm{T} \rho \mathrm{C}_{\mathrm{v}}}\right)\right] 1 / 2}\right. \\
& \vartheta_{\mathrm{c}}=\int_{0}^{\Gamma_{0}} \tau(\Gamma) \dot{\Gamma}\left\{\frac{1}{\rho}\left[\frac{\mathrm{n}}{\Gamma \tau}-\frac{v(1-\xi)}{\mathrm{T} \rho \mathrm{C}_{\mathrm{v}}}\right]\right\}^{1 / 2 \mathrm{~d} \Gamma}
\end{aligned}
$$

Preliminary numerical calculations have been performed to determine $\vartheta_{\mathcal{c}}$, assuming different strain rates at room temperature ; the material constants have been taken for XC18 steel : $\mathrm{B}=1092 \mathrm{MPan} ; \mathrm{n}=0.21$; $\mathrm{m}=0.0192 ; \vartheta=0.21 ; \rho=7.835 ; \mathrm{C}_{\mathrm{v}}=445 \mathrm{~J} / \mathrm{kgK}$ and $\xi=0,1$. In addition, different levels of the initial deformation $\Gamma_{\mathrm{i}}$ were considered : $\Gamma_{\mathrm{i}}=0 ; 0.50 ; 1.0 ; 1.5$ and 2.0 . Since the cold rolled steel was analysed the function $f_{2}$ was assumed as $f_{2}=\left(\Gamma_{0}+\Gamma\right)^{\mathrm{n}}$, with $\Gamma_{0}=0.44$. The final result is shown in Fig.4; it indicates that the order of $\vartheta_{\mathcal{c}}$ is correct. For example, for $\Gamma=0, \vartheta_{\mathcal{c}} \approx 129 \mathrm{~m} / \mathrm{s}$ and for $\Gamma=0.25, \vartheta_{\mathcal{c}} \approx 98.0$ $\mathrm{m} / \mathrm{s}$. these values are very close to the value found from Fig. 2 . 


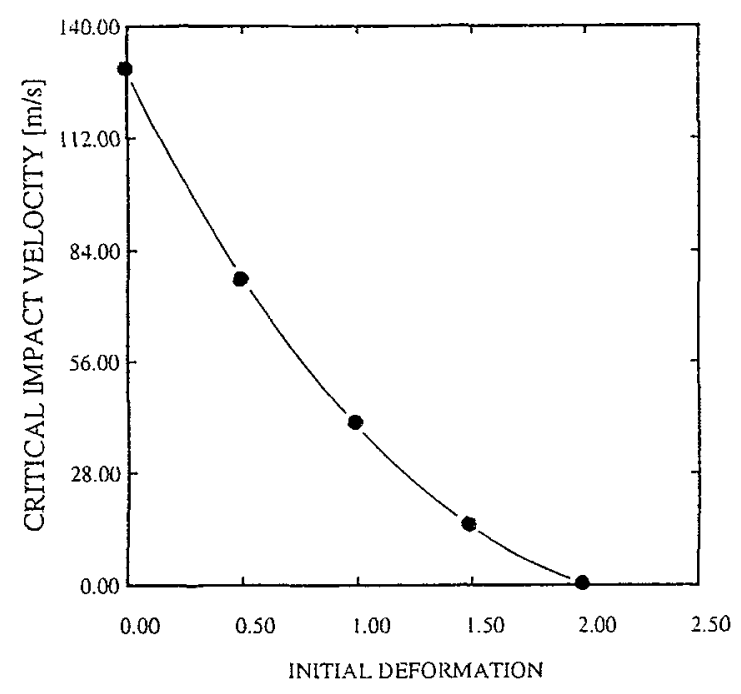

Fig.4

Acknowledgements - The research reported herein has been sponsored in part by the United States Army through its European Research Office, Contract DAJA 45-90-C-0052, and in part by CNRS-France.

\section{REFERENCES}

[1] Senseny P.E., Duffy J. and Hawley R.H., J. Appl. Mech. 45 (1976) 60.

[2] Costin L.S., Crisman E.E., HAWLEY R.H. and Duffy J., "On the localization of plastic flow in mildysteel tubes under dynamic torsional loading", Proc. $2^{\text {nd }}$ Conf. on the Mechanical Properties of Materials at High Rates of Strain (Inst; Phys. Conf. Ser. $\mathrm{N}^{\circ} 47$, Bristol, 1979) p.90.

[3] Giovanola J.H., Mechanics of Materials 7 (1988), part. I, 59.

[4] Giovanola J.H., Mechanics of Materials 7 (1988), part. II, 73 .

[5] Marchand A. and Duffy J., J. Mech. Phys. Solids 36 (1988) 251.

[6] Hartley K.A., Duffy J. and Hawley R.H., J. Mech. Phys. Solids 35 (1987) 283.

[7] Tong W. and Clifton R.J., J. Mech. Phys. Solids 40 (1992) 1251.

[8] Ferguson W.G. Hauser F.E. and Dorn J.E., Brit. J. Appl. Phys. 18 (1967) 411.

[9] Campbell J.D. and Ferguson W.G., Phil. Mag. 21 (1970) 63.

[10] Klepaczko J.R. "Adiabatic shear bands, review of experimental techniques and results", Anniversary Volume LMA (CNRS Marseille 1991) p. 335.

[11] Klepaczko J.R., Int. J. Impact Engng. 15 (1994) 25.

[12] Von Kàrmàn T. and Duvez P., J. Appl. Phys. 21 (1950) 987.

[13] Klepaczko J.R., Int. J. Mech. Sci. 10 (1968) 297.

[14] Recht R.F., J. Appl. Mech. 31 (1964) 189. 